\title{
BMJ Open One-year trial of 12-hour shifts in a non- intensive care unit and an intensive care unit in a public hospital: a qualitative study of 24 nurses' experiences
}

Solveig Osborg Ose, ${ }^{\ominus}$ Maria Suong Tjønnås, Silje Lill Kaspersen, Hilde Færevik

To cite: 0 se S0, Tjønnås MS, Kaspersen SL, et al. Oneyear trial of 12-hour shifts in a non-intensive care unit and an intensive care unit in a public hospital: a qualitative study of 24 nurses' experiences. BMJ Open 2019;9:e024292. doi:10.1136/ bmjopen-2018-024292

- Prepublication history for this paper is available online. To view these files, please visit the journal online (http://dx.doi org/10.1136/bmjopen-2018024292).

Received 21 May 2018 Revised 5 March 2019 Accepted 18 June 2019
Check for updates

(C) Author(s) (or their employer(s)) 2019. Re-use permitted under CC BY-NC. No commercial re-use. See rights and permissions. Published by BMJ.

Department of Health Research, SINTEF, Trondheim, Norway

Correspondence to Dr Solveig 0sborg 0se; solveig.ose@sintef.no

\section{ABSTRACT}

Objectives The aim of this study was to provide recommendations to hospital owners and employee unions about developing efficient, sustainable and safe work-hour agreements. Employees at two clinics of a hospital, one a non-intensive care and the other a newborn intensive care unit (ICU), trialled 12-hour shifts on weekends for 1 year.

Methods We systematically recorded the experiences of 24 nurses' working 12-hour shifts, 16 in the medical unit and 8 in the ICU for 1 year. All were interviewed before, during and at the end of the trial period. The interview material was recorded, transcribed to text and coded systematically.

Results The experiences of working 12-hour shifts differed considerably between participants, especially those in the ICU. Their individual experiences differed in terms of health consequences, effects on their family, appreciation of extra weekends off, perceived effects on patients and perceived work task flexibility.

Conclusions The results indicate that individual preference for working 12-hour shifts is a function of own health situation, family situation, work load tolerance, degree of sleep problems, personality and other factors. If the goal is to recruit and retain nurses, nurses should be free to choose to work 12-hour shifts.

\section{INTRODUCTION}

Hospitals are round-the-clock service providers, requiring staff that contribute to the efficient use of capital investments on days, nights and weekends. However, there is evidence of adverse physiological and psychological effects from shift work, including disruption to the biological rhythm, sleep disorders, health problems, diminished performance at work, job dissatisfaction and social isolation. ${ }^{1}$ The needs of hospital owners/managers and hospital employees are not always compatible, which can give rise to conflicts, work strikes and unions demanding a stronger voice in staffing decisions and working time arrangements.

One of the suggested solutions has been to introduce 12-hour shifts, which are becoming
Strengths and limitations of this study

A key strength of this study is its longitudinal design.

- The nurses trialled 12-hour shifts for 1 year, and their perspectives were obtained over an 18-month period that captured the nurses' views before, during and after the intervention.

- Another strength is the richness and authenticity of individual experiences that can be revealed by a qualitative methodology based on a relatively unstructured interview format.

- The study shows the heterogeneity of nurses' preferences for and ability to tolerate 12-hour shifts.

- A requirement for study approval was that the 12hour shifts would be voluntary. It is possible this study underestimates the risk of adverse outcomes from 12-hour shifts, as nurses who knew they would be susceptible to such outcomes likely chose not to participate.

increasingly common for hospital nurses. ${ }^{2}$ Hospital management may prefer 12-hour shifts instead of 8-hour shifts because longer shifts require fewer handovers and less overlap between shifts. Employees may prefer longer shifts to compress their work into fewer days. However, research has identified a wide range of associations between 12-hour shift work and negative outcomes for hospital nurses.

A systematic literature review of the effects of shift length in healthcare settings found that few studies were of moderate or high methodological quality, and that the results were difficult to compare because there is no standard measure of outcomes such as the quality of patient care. ${ }^{3}$ A newer systematic literature review concluded that there is strong evidence of a positive relationship between long working hours and adverse outcomes in nurses, but that more evidence is needed to determine the relationship to adverse patient outcomes. ${ }^{4}$ Another systematic review concluded that the risk of making 
an error appears higher among nurses working 12 hours or longer on a single shift in acute care hospitals. ${ }^{5}$ One systematic review of the safety implications of long work hours concluded that shifts longer than 8 hours are associated with a cumulative increase in the risk of accidents; for example, the risk of accidents after 12 hours is twice that after 8 hours of work. ${ }^{6}$ The authors of a recent systematic literature review suggest that 12-hour shifts may cause health problems and job dissatisfaction, but that this must be confirmed by more empirical evidence. ${ }^{7}$ We do not find other systematic reviews of hospital nurses working 12-hour shifts. Some cross-sectional studies report negative experiences from working 12-hour shift compared with 8-hour shifts, ${ }^{8-10}$ while other studies report positive experiences $^{11}$ or no risk. ${ }^{12}$ One comprehensive study based on a cross-sectional survey of 31627 registered nurses in 2170 general medical/surgical units within 488 hospitals across 12 European countries concluded that longer working hours are associated with adverse outcomes for hospital nurses, and that some of these adverse outcomes, such as high burnout rates, may pose safety risks for both patients and nurses. ${ }^{2}$

The topic of shift length is complex, and the results are not consistent across studies. The mixed results of studies of the effects of 12-hour versus 8-hour shifts in hospitals make it difficult for both employers and employees to make evidence-based decisions.

In the Norwegian democratic welfare state, public authorities are responsible for providing and financing health services. The responsibility for specialist care lies with the state (administered by four regional health authorities). The four regions have a total of 39 public hospitals and about 10 small private hospitals funded through contracts with the regional health authorities. The proportion of health professionals in the labour force is high in Norway compared with other high-/middle-income countries, ${ }^{13}$ and the quality of health services is high. ${ }^{14}$ The Conservative Party, in power since 2013, argued that long shifts in the health sector may be positive for both patients and employees. In 2015, changes to the Norwegian legislation on working hours in the health sector enabled employers and employees to implement long shifts without the approval of the National Labour Inspection Authority. Employers were now allowed to make deals with local unions permitting daily work of up to 12.5 hours. Working hours is an important area of conflicts between the nurses' union (Norwegian Nurses Organisation (NSF)) and hospital employer organisation (SPEKTER) in recent years.

In this study, we aimed to perform a thorough qualitative study, to understand nurses' experiences and perceptions of working 12-hour shifts compared with the usual 8-hour shifts. To our knowledge, no qualitative study has followed nurses working 12-hour shifts over a longer period. A qualitative longitudinal study may contribute to a better understanding of the mixed associations found in previous cross-sectional quantitative studies and may provide results with clearer policy implications.
The aim of this study was to understand the nurses' individual experiences. The objectives of the study were to (1) identify a hospital with plans for implementing 12-hour shifts, (2) recruit nurses who wants to share their experiences of working 12-hour shifts, (3) interview the recruited nurses before, during and after the trial period, (4) transcribe all interviews and conduct a systematic analyse of the data using applied social science research methods.

\section{METHODS}

\section{Study setting and design}

The hospital included in the study was a hospital in Norway. Two units were included: one gastrointestinal surgery ward (non-intensive care unit (ICU)) and a highly specialised newborn ICU. There were no male nurses working at either unit.

The trial was planned and conducted by the hospital while the qualitative study following the trial was performed by external researchers funded by the Norwegian Research Council and the social partners.

The qualitive study following the trial was planned together with managers and employees in the two units. The employees did not want to work 12-hour shifts on weekdays, because of concerns about patient treatment on the busier weekdays. The managers initially agreed to trial 12-hour shifts on weekends for 6 months, but this was extended to 1 year in both units. Only nurses were included in the study, not doctors or other personnel. Thirty nurses in the non-ICU and 12 in the ICU volunteered to try the 12-hour shifts, of whom 16 and 8, respectively, chose to participate in the qualitative study. They all agreed to be interviewed once before the trial started, during the trial and after the trial ended. Most of the individual interviews were conducted during a shift, but some interviews were difficult to organise within work hours and were conducted during the nurse's leisure time.

\section{Preparation}

Before the two units started the trial, the managers and employees agreed on a shift system with certain number of rest breaks during the 12-hour shifts and that only two 12-hour shifts should be worked per weekend (Friday included a regular 8-hour shift) and that the nurses would have the day before and the day after the work weekend off. They decided that the 12-hour shift should include $90 \mathrm{~min}$ rest breaks. The non-ICU decided to have one break lasting 1 hour and then a 30 min break while the ICU decided to have three breaks each lasting $30 \mathrm{~min}$.

Participation was voluntary, and employees were formally informed about what participation implied in a meeting with the researchers. Nurses with a history of high sickness absence were excluded from the trial, as the managers were concerned that 12-hour shifts would be too demanding for them and pose a risk to the trial. A pretrial meeting was also held in which the managers, union representatives and researchers discussed the trial 
and study with representatives from the National Labour Inspection Authority.

The ICU started their trial period on 5 September 2015; the non-ICU, on 1 April 2016.

\section{Data collection}

The recruited nurses were interviewed before, during and after the trial period. Three semistructured interview guides were developed by the research team to cover the situations before, during and after the trial. The pretrial interviews lasted $1-1.5$ hours, the in-trial interviews lasted $\sim 1$ hour and the post-trial interviews lasted 30-40 min. All participants provided written consent at the pretrial interview. Seventy interviews were conducted by three researchers, as two participants were lost to follow-up due to job change. The interviews were conducted in the Norwegian language. The 18-month data collection period was August 2015 to January 2017. All interviews were audiotaped and transcribed verbatim.

\section{Emergent themes}

Projects that involve many interviews produce a vast amount of data or text that is difficult to structure and analyse systematically. A 10-step method has been developed to code and structure text using Microsoft Word and Excel. ${ }^{15}$ This 10 -step method produces a flexible Word document of interview data separated into logical chapters and subchapters. All text is coded, and the codes correspond to headings in the final document. Systematic manual coding ensures that all the content is coded, not just words or terms extracted from the text. In this study, 140 codes were used. Examples of codes are 'work environment', 'organisation of rotation plans', 'experiences during the 12-hour shifts' and 'family consequences of 12-hour shifts'. The multidisciplinary team that conducted the interviews coded all interviews. We developed the code list together at the beginning of the coding process, coded the same interviews and revised the code list several times during the process. All transcribed interviews were fully coded (ie, all transcribed text was assigned a code). In this study, we analysed data under the main heading of '12-hour shifts'. The remaining data provide information about the hospital and unit context. This information is not used explicitly in this study. Using the 10-step method, we identified the following main topics for the analysis: 'pretrial expectations of working 12-hour shifts on weekends', 'organising and implementing the 12-hour shift schedule', 'consequences of working 12-hour shifts' (with subheadings 'positive/negative effects during the shift', 'positive/negative effects during the off-shift periods', 'sleep', 'quality of treatment', 'health problems' and so on), 'decision after the end of the trial period' and 'individual overall assessment'. The results section is organised under these headings. We have included quotations that reflect the themes that emerged from the systematic coding process.

\section{Patient and public involvement}

This health services research study includes employed public hospital nurses. Both the employer organisation and the nurses' union were involved from the beginning of the project to the end.

\section{RESULTS}

The difference in the type of care at the two units was reflected in the staff experience and education levels: the non-ICU had many young nurses who had not completed any specialised training, and it had relatively high turnover; the ICU had more-experienced staff, most of whom had a specialisation. The non-ICU had $\sim 60$ nurses; the ICU 120 nurses. Most nurses at both units worked a rotating three-shift schedule (day, evening, night), but some worked exclusively days or evenings, and others only overnight shifts. Patients stayed from 1 day to several months in both units.

\section{Expectations before starting the 12-hour shifts}

All participants expressed their excitement about starting 12-hour shifts. Participants were asked, 'What do you expect will happen when you start working 12-hour shifts on the weekends?' without any explicit cues. We have organised the answers into topics according to the how the responses were coded.

\section{Not much difference from the current situation}

Some of the nurses in both units thought it was difficult to have any expectations because the work load was generally unpredictable. Some periods were very busy, with many severely ill patients, whereas other periods were less busy. The nurses in the non-ICU thought that the long shifts might occur during peak periods, and some expressed concerns about this.

It can be very busy here, so it [working 12 hours shifts] will be difficult because you do not have time to be tired during a busy day shift. At night, when you are tired because it's night time, a busy shift will be very tough (Nurse 14, non-ICU, pre-trial interview).

Many of the nurses in the ICU were used to working double shifts, and they did not expect the 12-hour shifts to be more difficult.

\section{More tired}

Most of the respondents expected to be more tired after a weekend working 12-hour shifts compared with a weekend working 8 -hour shifts (ie, 8 hours more than usual for a day-shift weekend):

I think I'll be very tired from working that weekend.

It is good that we'll have the Monday after off, so we can get our strength back before starting the next shift (Nurse 13, non-ICU, pre-trial interview).

When we asked whether they were tired after a regular 8-hour shift, they typically answered: 
It varies a lot depending on my work tasks and the amount of pressure at the unit. But I'm tired at the end of a regular 8 hour shift if it's a busy day (Nurse 2, ICU, pre-trial interview).

The participants in both units confirmed that they were exhausted after a busy shift. However, most recovered well before the next shift, although problems obtaining sufficient sleep between an evening and morning shift were common.

\section{Nights}

Some participants worked only nights. They typically expected that the 12-hour shifts would not be significantly different:

The night shift is rather long already-it's 10 hours now. When I start doing 12 hours shifts, I will start at $7.45 \mathrm{pm}$ instead of $9.30 \mathrm{pm}$. The difference is not that big, and I'll get to have a 1 hour break during the shift. I think it will be beneficial to start earlier in the evening (Nurse 10, non-ICU, pre-trial interview).

Those working both day and night shifts during their 12-hour shift weekends shared this view about the nights.

\section{Health concerns}

Some respondents were not concerned about potential adverse health effects from working 12-hour shifts, not because they thought such shifts would be healthy, but rather because it was already difficult to work a rotating three-shift schedule. However, others did express concerns:

I'm cursed with neck pain when I'm stressed. I'm wondering whether my back and neck will handle it [to work 12 hours shifts]. But as long as I get to take rest breaks during the shifts, I think I'll be fine (Nurse 10, non-ICU, pre-trial interview).

\section{Attitude and mental preparation}

Several of the respondents argued that the experience would largely depend on their attitudes: 'If you say to yourself that this is not going to work out well, it will not work out well. Participants in both units felt this way, but this is also related to personality:

I don't really have any specific concerns; I usually take things as they come. I'm thinking that this weekend will be about work and nothing else; it doesn't matter that there are some more hours (Nurse 16, non-ICU, pre-trial interview).

However, some ICU nurses were not convinced that the introduction of 12-hour shifts would be that easy. They reflected on the need to prepare mentally for the long shift:

I want to try working 12 hours shifts, but I am not sure because I haven't tried this before. Maybe I won't like it. But I think I'll have to be mentally prepared because on days when I usually finish at $3 \mathrm{pm}$, I will now have to work until $7.30 \mathrm{pm}$ (Nurse 1, ICU, pre-trial interview).

\section{Patient consequences}

The nurses in the ICU seemed to be more concerned than the nurses in the non-ICU about potential adverse consequences for patients of nurses working longer shifts:

I'm not sceptical...but I think we must find out whether 12 hours shifts will increase the probability of making mistakes. Will we be totally exhausted? -At the end of the shift, will we be unable to do anything? Will we be able to do the work tasks we are supposed to do? (Nurse 1, ICU, pre-trial interview).

The staff in the newborn ICU had strong focus on quality; for example, two colleagues would always doublecheck medicine prescriptions (double-signing). They wondered whether they might be too tired at the end of the 12-hour shifts to sustain quality:

If you have a family making many demands or a newborn who needs constant monitoring, it will be demanding to work 12 hours with the same patient and family. At the end of the shift, there might be a small risk of making mistakes; for instance, we might overlook that the infant's condition has worsened... (Nurse 6, ICU, pre-trial interview).

\section{Effect on leisure and family life}

Several of the respondents expressed concern about how the 12-hour shifts would affect their family life.

Well, I'll have to see how this works out with the rest of my life. It's not just that I'll be at work for more hours, it's that this must also fit my life outside work (Nurse 1, ICU, pre-trial interview).

However, the criteria for selecting participants imply that most of the respondents had a family situation that allowed them to try the 12-hour shifts on weekends.

\section{Enthusiasm and resistance}

Some had great expectations about introducing the 12-hour shifts:

My expectations are first and foremost that 12 hours shifts will be introduced as a permanent arrangement and that this will lead to an improved quality of nursing both for the newborn patients and parents (Nurse 5, ICU, pre-trial interview).

Others were indifferent. When we asked about the atmosphere at the units in relation to the 12-hour shift trial, a typical answer was:

Well, some of the nurses are happy to try 12 hours shifts, but others do not want to. But I do not think there has been any strong protest against the trial (Nurse 10, non-ICU, pre-trial interview). 
Those unwilling to try 12-hour shifts typically had small children. Their colleagues who chose to participate in the trial showed understanding:

It's easy to understand if they [nurses who do not want to try 12 hours shifts] have kids. Working a regular 8 hour shift allows you to see your kids before and after work, but this is different when working 12 hours shifts: they are in bed when you come home and still asleep when you leave for your next shift (Nurse 12, non-ICU, pre-trial interview).

\section{Organising the 12-hour shift schedule}

The planning and organising of the 12-hour rotating shifts was not problematic in the non-ICU but was frustrating for those responsible for the rotation plans in the ICU. The ICU had eight nurses working 12-hour shifts on the weekends: four on day shifts and four on night shifts. In general, the rotation plans in the ICU unit were complicated. The unit divided all nurses into three groups, and every shift team within each group had to include the right formal competencies, and a specified mix of nurses with extensive experience and those with less experience. The planners had to consider adjustments because of the patient mix and for individual employees. For example, some nurses were insufficiently experienced to feel comfortable working alone with very sick infants. Others did not have the competencies to comfortably perform all the specialised roles and tasks that might be required of them during a shift, based on the skills mix of their on-shift colleagues. A willingness to adjust the schedule to accommodate individual employee preferences, together with meeting other competency and experience profile criteria for every shift, made planning a rotating roster a complex task. The addition to this complexity by having to include 12-hour shifts caused frustration for the planners. However, the trial period was extended by 6 months, and the planners said that planning the 12-hour shifts became easier as they gained experience.

\section{Consequences of working 12-hour shifts \\ Taking rest breaks as planned}

We asked participants whether they could take rest breaks as planned when they worked 12-hour instead of 8-hour shifts, and most of the respondents did not experience any difficulties.

That went as planned. One weekend, my rest break was moved half an hour, but that was okay. It was right after an 8 hour shift started, and there were too few experienced nurses on duty, so I felt I couldn't take my break exactly when planned. But otherwise, I think we could all take the planned rests and pauses (Nurse 1, ICU, in-trial interview).

The non-ICU had a room with a bed for the nurses' use, for napping and relaxing for 1 hour when working 12-hour shifts. Their experience with this was positive.
That [the bed in a designated room] was very comfortable. Nobody called me on my phone and no one came into the room. The others respected this hour [for rest], and the threshold for knocking at that door was high (Nurse 1, non-ICU, in-trial interview).

However, not all respondents had good experiences trying to nap during their shift:

Well, I slept once or twice during my 1 hour break during the night shift. But when I woke up I was feeling queasy. I was very tired when I woke up and felt off-balance. So, I have stopped napping during the 12 hours night shift (Nurse 10, non-ICU, in-trial interview).

We asked how the she spent that hour during the following 12-hour night shifts afterwards. She answered:

I can lie down for a little while, but I keep the lights on. I can listen to music or watch TV on my mobile (Nurse 10, non-ICU, in-trial interview).

Some created their own mix of activities during the 1-hour break at night:

In my break during the night, first I sleep half an hour and then I watch a film or an episode from a TV show. The first few times, I slept for the whole hour, but I was unwell when I woke up, and I couldn't sleep when I got home. After I started with half an hour of sleep and half an hour watching something, I felt much better (Nurse 13, non-ICU, in-trial interview).

Another nurse working in the non-ICU described her experience:

I'm a bit queasy at first when I wake up, but I'm okay once I get on my feet. I think it is safer to have this nap because I have to drive home after the night shift (Nurse 11, non-ICU, in-trial interview).

One of the respondents had a more determined approach to sleeping:

Yes, I was able to get some sleep during both the day shifts and the night shifts. I have become quite good at power napping, and I had decided that I wanted to be good at that. I was not very good at it before, but now I can do it. I fall asleep quite simply now (Nurse 7 , non-ICU, in-trial interview).

Some of the nurses went outside during their break for fresh air, especially if the weather was pleasant. Others rested before their shift, saying that they did not need to sleep, but it still felt good to lie down and relax, and to think about something other than work.

However, working in a hospital entails a level of uncertainty, and many unplanned events during the shift can make it impossible to take the planned rest breaks.

Last weekend, on the first night, I had two emergency patients who were very ill. There was much uncertainty about whether they had to be operated on during 
the night. In addition to these two, I had one uneasy patient and one mentally ill patient who needed constant monitoring. The night after, at $1.30 \mathrm{am}$, the alarm sounded because a patient had a cardiac arrest, and we had to use the defibrillator and perform chest compressions. I think it took 2.5 hours before we got the patient to the ICU. That weekend, I did not get my 1 hour rest break during any of the night shifts (Nurse 2, non-ICU, in-trial interview).

\section{Health consequences}

The nurses in the non-ICU discussed the health effects of working 12-hour shifts. Some of the nurses did not feel any difference compared with working 8-hour shifts, but they needed the day off after the work weekend to recover. Others described different negative experiences of working longer shifts than usual:

At the end of the shift, I had a headache and my eyes were dry and sore from the dry air in the unit. I felt like I had been at work for a long time (Nurse 15, non-ICU, in-trial interview).

Others mentioned health problems that may have been worsened by working long shifts:

The night-shift weekends are very demanding, but fortunately, they only occur every 8 weeks. The weekends with the day shifts are okay, but I have back problems, and my back is sore after work weekends. Maybe I should not work in this way, but the carrot is, of course, that I get to work every fourth weekend instead of every third weekend (Nurse 11, non-ICU, in-trial interview).

Most of the participants felt greater fatigue in their legs after a 12-hour shift, but some did not, despite the longer time spent standing and walking compared with an 8-hour shift. Most of the respondents described having a 'tired head' after a 12-hour shift, but few reported any unexpected physical pain or health problems.

I think it has been okay, but I get a burning sensation under my feet, and feel tired. And, of course, at the end of the shift on the first weekend, I really hoped there would be no childbirth in the evening. You think such thoughts (Nurse 6, ICU, in-trial interview).

Another nurse had the opposite experience:

I worked 12 hour day shifts both Saturday and Sunday. It occurred to me that I can't remember the last time I wasn't exhausted after a shift. But this weekend, my legs were less tired than on a regular work weekend. I wasn't physically tired at all from working this weekend (Nurse 5, ICU, in-trial interview).

Some of the participants found it more difficult to work 12-hour day shifts than 12-hour night shifts:

The days are a bit longer than the nights. The difference between a 10 hours and 12 hours night shift is small, but the day... You need better shoes because your legs get tired (Nurse 3, ICU, in-trial interview).

The nurses in the non-ICU expressed uniform satisfaction with the opportunity to lie down during the 1-hour break:

I do not feel more tired than usual. I feel the night shifts are very good, with the 1 hour rest break. It is almost the worst [to work] the night before Saturday, because then we work a regular night shift without the mandatory break. I almost look forward to the next night when I work 12 hours and get to have a break for a whole hour (Nurse 13, non-ICU, in-trial interview).

\section{Patient outcomes}

None of the respondents admitted to making any mistakes during their 12-hour shifts, but they were not always sure:

I did not make any mistakes. But one thinks about it-after 11 hours, it could be easy to misread a graph, or something similar. Not that it has happened, but we are not as awake at the end of the shift as at the beginning (Nurse 2, non-ICU, in-trial interview).

When asked about observed patient outcomes, some nurses said that they did not think patients noticed much difference. Some patients in the non-ICU had observed that some of the nurses were present for a long time, and had asked them about this. The nurses did not receive any negative reactions from the patients after explaining the trial, only positive responses. They also adjusted their rest break to their work tasks to minimise the consequences for the patients.

I take my rest break after I have finished distributing medication, pain relievers, and meals, so my patients don't often need to call for someone else during my break (Nurse 13, non-ICU, post-trial interview).

\section{Family situation and friends}

Most respondents felt that the most important positive consequence of working 12-hour shifts was only having to work every fourth weekend, instead of every third. They felt this was important because of their family situations.

[Working] every fourth weekend instead of every third is very important to me, especially since my second child was born. It's okay to have time off during the weekdays, but this is not when my family has time off. So weekends off are very precious to me (Nurse 1 , non-ICU, in-trial interview).

Some nurses had asked their family explicitly what they thought about the 12-hour shifts:

They are happy I'm home on more weekends. Whether I work a 12 hours or 8 hour shift during the weekend does not matter to them. Maybe I sleep more during the regular work weekends, so the kids do not 
see me much on these weekends anyway (Nurse 11, non-ICU, in-trial interview).

Individual family situations sometimes necessitated adjustments to the work schedule:

I have my son every second weekend, and this is the only reason for me to work the 12 hours shifts every fourth instead of every third weekend (Nurse 16, non-ICU, in-trial interview).

Some of the nurses without children also valued the weekend more than weekdays for many reasons:

...none of my friends outside of work do shift-work, so for me, the weekends are sacred (Nurse 15, nonICU, in-trial interview).

Family needs could be demanding for nurses with young children. For example:

As a joke, I say that my job at the hospital is my second job, because my main job is at home. I have many things to keep track on at home, and when I have a work weekend, I still want to be with the kids. I feel bad about going to work, so when I get up in the morning, I must organise everything [my kids might need]. But when I work 12 hours shifts, I say to myself, 'Okay this is my work weekend', and then I concentrate on that and think about the fact that I have three weekends off afterwards when I can be with my children (Nurse 7, non-ICU, in-trial interview).

All participants who were married noted that their husbands wanted them to work 12-hour shifts every fourth weekend instead of 8-hour shifts every third weekend.

My husband wants me to work the 12 hours shift weekends. He takes the kids to visit their grandparents on my work weekends and I have a quiet house. This is fine for them and for me (Nurse 13, non-ICU, in-trial interview).

A more experienced nurse with adult children also noted that her husband liked this arrangement:

My husband thinks this is fine, because we can go to our holiday cabin on more weekends than before. And on my work weekend, he can go to the cabin alone, because all I do that weekend is work (Nurse 8 , ICU, in-trial interview).

However, others felt they missed out at home when they worked a long shift on Saturday:

It was wonderful to get home at $8 \mathrm{pm}$ on Saturday night and have a nice meal and relax with my boyfriend. This gave me a bit more of a weekend feeling. Two or three hours of rest before going to bed was good. Now, I get home at $10.30 \mathrm{pm}$ and feel I must rush to bed to get enough sleep before the next shift (Nurse 2, non-ICU, in-trial interview).
Tasks at work

Many of the participants experienced greater flexibility during the 12-hours shift than the 8-hour shifts.

The 12 hours night shifts have been terrific. I have a much better overview when I arrive at $8 \mathrm{pm}$ and can start the evening round of medicines, start to get the antibiotics ready, organise the medicine for the next day, and so on. And I finish my round earlier compared with when we start working at 9.30 or $10 \mathrm{pm}$ (Nurse 10, non-ICU, in-trial interview).

The nurses also commented that they experienced fewer interruptions of work tasks during the 12-hour shifts:

I noticed this at the time that would have been the regular shift change [had it been an 8 hour day], when we were in the middle of a procedure, on one of the days when I worked the 12 hour day shift. I was assisting a doctor with a lengthy procedure, and usually one gets a bit stressed at such times, because we have to finish the report and everything else before the next shift starts at $2.30 \mathrm{pm}$. And then I thought, 'God, this is actually very good', because I could relax and concentrate on what I was doing, and I took my time and calmly finished the procedure around $4 \mathrm{pm}$. Usually, I would have to hand over to the next nurse during the procedure and give a short oral report. We lose continuity this way, because the doctors are there the entire day. So I think it's better for all [having 12 hours shifts]. I didn't have a ticking clock at the back of my mind all day (Nurse 1, ICU, in-trial interview).

This nurse also commented on the satisfying experience of completing jobs on her own, rather than having to leave them to the next shift:

And I feel that I get to do what I'm supposed to do on the days I work 12 hours shifts. Instead of telling the next nurse what I have planned to do, I do it myself. Because I can't be sure that the next nurse has the same priorities and will do what I planned (Nurse 1, ICU, in-trial interview).

Being present in the unit for a longer time may make the job easier because the nurses can prepare and get to know patients better. During the trial period, the participants always worked on the Friday before. Some noted that this prepared them better for the long shifts on Saturday and Sunday because they knew what to expect, having learnt more about the patients in the ward.

Several participants also felt they could plan and structure a long shift better:

The ward is usually busy, and I have had work weekends where I have been very tired and have been very happy to go home at $3 \mathrm{pm}$. However, I have not always been happy with my work, because too much was left for the next shift [to finish]. Now I can plan better 
and complete all my tasks (Nurse 9, non-ICU, in-trial interview).

Other nurses reported similar experiences:

If you've promised the parents the infant will have a bath, you don't have to stress and do it early in the day; you can plan to find a calmer period, to have more time available for the task (Nurse 9, ICU, in-trial interview).

Another nurse at the same unit had similar experiences working night shifts:

I think I do the same as usual. However, I think I have more time to do my tasks. Nothing must be done right away because I'm going to be here until the next day (Nurse 4, ICU, in-trial interview).

\section{Decisions after the end of the trial period}

The manager at the ICU decided not to continue the 12-hour weekend shifts after the trial period, whereas the manager at the non-ICU decided to allow more nurses to try out this approach.

For the nurses in the non-ICU, working fewer weekends and being able to provide a higher quality of care were the main reasons for continuing to work the 12-hour shifts. Some participants had not expected the 12-hour shifts to be successful in this very busy unit, but realised that they liked working longer shifts:

I liked working 12 hours shifts very much. I was sceptical the first time I heard about it, but I wanted to try. I think they are suitable for me [because] I have good capacity to work, and think that when I'm at work, I like to work hard. I can tolerate this [way of working], but I have not been sick and I can handle the pressure quite well (Nurse 7, non-ICU, post-trial interview).

The participants from the ICU reported mixed experiences at the end of the trial period. Some were unhappy about the decision not to implement 12-hour shifts as part of the regular schedule once the trial period was finished. They argued that this decision was only made because the schedule planners found it difficult to implement 12-hour shift schedules. When one participant was asked whether the scheduling process could be made easier if the unit were organised differently, she replied:

Yes, without doubt. If we were divided into two groups instead of three it would be much easier to make up the shift plans. We would have more people to choose from and that would give more flexibility (Nurse 7, ICU, post-trial interview).

Another nurse in the ICU also wanted the 12-hour shifts to be continued, and shared the following experience after the trial ended.

Now I see a lot of work weekends on my shift plan. I experienced a significant difference between working every fourth and every third weekend. Now, there are more conflicts with other things that happen outside work. I did not experience this to the same extent when I worked every fourth weekend (Nurse 1, ICU, post-trial interview).

Others were indifferent about the decision not to continue the 12-hour shifts:

I haven't really engaged in this discussion; I just noticed that they didn't want to continue. My first thought was that it [the decision] sucked, but then I decided to focus my energy on doing my job instead (Nurse 5, ICU, post-trial interview).

A small group of nurses had decided not to continue with the 12-hour shifts before management decided not to continue. Not all nurses shared a clear preference for avoiding working on weekends:

Well, I don't have small children. For some, the 12 hours shifts are better-for instance, those only working night shifts and those who have to commute longer distances (Nurse 4, ICU, post-trial interview).

Well, it is good to have an extra weekend off, but I must work much more during the weekdays Monday to Friday. That's what everybody else does. But I'm happy working shifts with more time off on weekdays (Nurse 2, ICU, post-trial interview).

Some ICU nurses who had been sceptical before the trial had positive experiences and wanted to continue. Others who had been positive before the trial did not want to continue working 12-hour shifts after the trial. This indicates that it may be difficult for nurses to anticipate their own preferences for shift lengths accurately, before trying them in practice.

\section{DISCUSSION}

This qualitative longitudinal study followed nurses for 18 months before, during and after they trialled working 12-hour shifts on weekends for 1 year. Their participation in the 12-hour shift work was completely voluntary, and only those motivated to work the 12-hour shifts participated. The aim of the study was to understand the nurses' individual experiences. Their perceptions give insight into the potential consequences of any future reform to increase the standard shift length for hospital nurses from 8 to 12 hours. In the following sections, we discuss the themes that emerged from this research: job satisfaction, health effects, effects on sleep, patient safety and employee safety.

We asked all respondents how they perceived their work environment and all participating nurses had favourable perceptions of their work environment. This may be an important condition for implementing new shift arrangements. The ICU was reorganised when the trial period started, and all nurses were divided into three groups with different tasks. During the interviews, it appeared that not 
all employees were satisfied with the new organisation of the unit. Their main argument against the reorganisation was that they had each ended up with a narrower spectrum of work tasks than desired. Such changes may have negative impact especially on job satisfaction.

\section{Job satisfaction}

Job satisfaction was high overall among the participants. In the non-ICU, the nurses were generally happy that the use of 12-hour shifts would continue, and more nurses wanted to try the extended shifts. In the ICU, the nurses had mixed reactions to the managers' decision not to continue the 12-hour shifts. Some thought this was a poor decision; others were indifferent or supportive. Overall job satisfaction at the units does not appear to have been affected by the 12-hour shifts. However, different preferences may affect the nurses' ongoing job satisfaction at the individual level. This is consistent with the findings of Kundi et al, ${ }^{16}$ who found similar levels of job satisfaction between 8-hour and 12-hour shift workers. In our study, only volunteers were included, and no one was forced to work the extended shift against their will. This study therefore cannot rule out the possibility of negative consequences on job satisfaction if nurses are forced to work longer shifts, rather than volunteering.

\section{Health effects}

Because participation was voluntary, and the same nurses were followed for 18 months, this study was able to probe factors behind the stress and burnout reported in the literature. ${ }^{289}$ Because the 12-hour shift was implemented only on weekends, we expected to see less significant effects on health and well-being among the participating nurses compared with those working 12-hour shifts throughout the week in other studies. Most of the participants in our study experienced a greater physical and mental workload during 12-hour shifts compared with 8-hour shifts. This was mainly because of the longer time spent walking and standing and being exposed to the dry air in the units. A recovery period was needed after a 12-hour shift weekend. The nurses commented that pre-existing health problems might be worsened by working long shifts. Some had health concerns before they started the trial, but still felt that there were advantages of working every fourth instead of every third weekend and wished to continue. It is possible that these nurses overlooked or underreported negative health consequences of the longer shifts. We suggest that negative health effects of 12-hour shifts will be significant if employees with health problems are forced to work longer shifts than they can tolerate given their health status.

\section{Effects on sleep}

The literature shows that nurses accrue considerable sleep debt while working successive 12-hour shifts, with accompanying fatigue and sleepiness, and that some nurses are more severely affected by sleep loss than others, as measured by attention lapses. ${ }^{10}$ In this study, the 12-hour shifts were worked only on weekends and were voluntary, and the effect on sleep was expected to be slight. We find that those who reported sleeping problems in the pretrial interviews had the same sleeping problems when they were working 12-hour shifts. None of the participants reported having sleep problems from starting to work 12-hour shifts. However, we cannot rule out the possibility that the nurses who self-selected to participate were less susceptible to sleep problems than those who opted out. However, of the 24 participants, many reported sleeping problems in the pretrial interviews, so the opposite may also be the case. We suggest that the observed variation in individual sleep quality gives an important argument for hospital owners to offer the nurses and other employee different choices of working hour agreements.

\section{Patient safety}

There is some evidence that longer work hours for hospital staff can increase the risk of errors and hospital-associated infection among patients. ${ }^{17} 18$ However, a systematic literature review concluded that more evidence is needed to conclude whether there is a causal relationship between long work hours and adverse patient outcomes. ${ }^{4}$ In this study, all participants acknowledged that the risk of mistakes was higher at the end than at the beginning of a shift. However, none of the nurses reported making mistakes during the trial period.

One finding that is rarely reported in the literature is a positive effect on patients and the quality of care from longer nurse work hours-yet this was reported by our participants. Most felt they had more time to complete their tasks, and the opportunity to follow their patients for longer during each shift.

We did not interview the doctors, and we do not know whether this trial had any effects on them. However, it is plausible the doctors benefited from having fewer disruptions during procedures for hand-overs between the nurses working different shifts, and from having fewer nurses to communicate with during the day.

The 12-hour night shifts were perceived to work well in this trial, especially in the non-ICU, where nurses had their own room with a bed for resting. A recent study reported that 12-hour night shift workers exhibit more performance variability and subjective sleepiness than day workers, and suggests that workplace napping may be considered. ${ }^{19}$ We find that the 1-hour rest break available to the nurses working 12-hour night shift in our study, was very appreciated by the nurses. The 1-hour break was used in various ways by the nurses, and most satisfaction was expressed by those who had access to a designated room with a bed where they could lay down in their 1-hour rest break during the night shift. This arrangement may have contributed to the lower level of sleepiness and performance variability self-reported by nurses in our study.

Turning to the long duration of night shifts in this study, the participating nurses had positive experiences with the 12-hour night shifts overall. Several factors may account for this. Notably, all participants in the medical 
unit felt that having a bed in a designated staff room for rest breaks during the long night shifts was an advantage. This may be an effective method for reducing the increased risk of accidents in long shifts reported in the literature. ${ }^{6}$

\section{Employee safety}

Shift work generally, and night shifts and long shifts in particular, are frequently associated with adverse effects on employees. However, this study found mixed views on the employee safety implications of longer (12 hours) shifts, including for the night shifts.

On the one hand, the managers of both units argued that 'pure' night shift workers became an isolated group, whom the managers never met and who did not receive the professional updates received by nurses working days and evenings. They therefore wanted the night shifts to be spread among more nurses, and had reduced the size of the designated pure night team, that is, the nurses working night shifts exclusively.

On the other hand, this change was not preferred by most of the nurses-regardless of whether they wanted to work primarily nights or did not handle night work well. The literature suggests a possible explanation. Wagstaff and Sigstad $\mathrm{Lie}^{6}$ concluded that pure night work may provide some protection against the negative health effects often reported from intermittent night shift work, by allowing resynchronisation. Therefore, there may be good arguments for reintroducing pure night shift teams. Moreover, if night shifts are 12-hour long, the alienation mentioned by managers may be reduced, because the night shift nurses arrive earlier in the evenings to start their shift and therefore participate in some of the same activities as nurses working the evening shift. On the other hand, some nurses did not want to change from a two-shift system to a three-shift system. This may be explained in part by a recent study of combined in-field and laboratory experiments that concluded that chronic shift work causes night shift intolerance. ${ }^{20}$

\section{An overall evaluation}

We agree with Ferguson and Dawson, ${ }^{21}$ who concluded that there is no simple 'yes or no' answer to the choice between 12-hour versus 8-hour shifts. They argued that the answer depends on the context, including the work tasks, workforce and workplace. However, we wish to add another dimension: individual preferences.

Individual nurses' preferences are heterogeneous even within the same unit. It is not easy to obtain a clear picture of the diversity of preferences using quantitative methods. Moreover, a given individual's preference will change over time as her or his family and health situation evolves, and depending on the situation at work. Therefore, no universal decision about shift length preferences is possible; rather, continuous dynamic assessment of the most suitable shift length and rotation scheme for each employee is needed, if the aim is to reduce the adverse outcomes of shift work.
The scoping review by Harris $e t a l^{22}$ suggests that there may always be insufficient evidence to justify either the widespread implementation or the withdrawal of 12-hour shifts for nurses. They concluded that the real benefits, and whether there are real and unacceptable risks to patients and staff, are unknown. They also noted that more research is needed to understand the long-term effects, as opposed to more easily measured short-term effects.

We suggest that the mixed results in previous studies reflect the fact that there is simply no universally correct answer to this question, because of the differences in context but also the heterogeneity and dynamic nature of individual preferences and tolerance. We argue that the observed diversity of expectations and experiences, and the strength of different nurses' contrasting preferences about long shifts, indicate that 12-hour shifts should be completely voluntary, rather than being either mandated or banned as a universal policy.

\section{STRENGTHS AND LIMITATIONS}

A key strength of this study is its longitudinal design. The nurses trialled 12-hour shifts for 1 year, and their perspectives were obtained over an 18 month period that captured the nurses' views before, during and after the intervention. Another strength is the richness and authenticity of individual experiences that can be revealed by a qualitative methodology based on a relatively unstructured interview format.

A key limitation is the small sample size of 24 nurses. However, given that our qualitative research design based on interviews was unsuitable for very large sample sizes, a more important limitation is that we excluded nurses who did not wish to trial the 12-hour shifts. It is possible this study underestimates the risk of adverse outcomes from 12-hour shifts, as nurses who knew they would be susceptible to such outcomes likely chose not to participate. This aspect of the study design was determined by ethical considerations: as it would be highly unethical to force someone to work 12-hour shifts against their will, a requirement for study approval was that the 12-hour shifts would be voluntary. Additionally, we suspect that negative health consequences of working 12-hour shifts were underreported by the participants, as many wanted the trial to succeed so they could work only every fourth weekend instead of every third weekend.

Another limitation is that only female nurses participated in the study.

\section{CONCLUSION}

This study revealed the diversity of nurses' preferences for working 12-hour shifts. While the experience of working 12-hour shifts was positive for most of the participating nurses in our study, it was not universally preferred. We suggest that individual preference for working 12-hour shifts is a function of own health situation, family 
situation, work load tolerance, degree of sleep problems, personality and other factors.

Based on these findings, we recommend that working 12-hour shifts in public hospitals should be voluntary. Pushing nurses into working long shifts against their will could negatively affect their health, job satisfaction and general life quality, and drive them away from the profession.

Contributors $\mathrm{HF}$ and S00 wrote the project proposal and obtained funding. S00, MST and SLK conducted the interviews. MST, SLK and SOO coded all the interviews based on a code-list developed by the team of all authors. SOO drafted the manuscript and the other authors contributed significantly to the final version.

Funding This project was funded mainly by the Research Council of Norway. The main hospital employer organisation (SPEKTER), the nurses' union (NSF) and the nursing assistants' union (Fagforbundet) financed the same yearly amount covering in total one-fifth of the project's total cost.

Competing interests None declared.

Patient consent for publication Not required.

Ethics approval This study was approved by the Regional Committees for Medical and Health Research Ethics in Mid-Norway (REC) (reference number 2014/2017).

Provenance and peer review Not commissioned; externally peer reviewed.

Data sharing statement No data are available.

Open access This is an open access article distributed in accordance with the Creative Commons Attribution Non Commercial (CC BY-NC 4.0) license, which permits others to distribute, remix, adapt, build upon this work non-commercially, and license their derivative works on different terms, provided the original work is properly cited, appropriate credit is given, any changes made indicated, and the use is non-commercial. See: http://creativecommons.org/licenses/by-nc/4.0/.

\section{REFERENCES}

1. Admi H, Tzischinsky O, Epstein R, et al. Shift work in nursing: is it really a risk factor for nurses' health and patients' safety? Nurs Econ 2008;26:250-7.

2. Dall'Ora C, Griffiths P, Ball J, et al. Association of $12 \mathrm{~h}$ shifts and nurses' job satisfaction, burnout and intention to leave: findings from a cross-sectional study of 12 European countries. BMJ Open 2015;5:e008331.

3. Estabrooks CA, Cummings GG, Olivo SA, et al. Effects of shift length on quality of patient care and health provider outcomes: systematic review. Qual Saf Health Care 2009;18:181-8.
4. Bae SH, Fabry D. Assessing the relationships between nurse work hours/overtime and nurse and patient outcomes: systematic literature review. Nurs Outlook 2014;62:138-56.

5. Clendon J, Gibbons V. $12 \mathrm{~h}$ shifts and rates of error among nurses: A systematic review. Int J Nurs Stud 2015;52:1231-42.

6. Wagstaff AS, Sigstad Lie JA. Shift and night work and long working hours--a systematic review of safety implications. Scand J Work Environ Health 2011;37:173-85.

7. Banakhar M. The impact of 12-hour shifts on nurses' health, wellbeing, and job satisfaction: A systematic review. J Nurs Educ Pract 2017;7:69.

8. Iskera-golec I, Folkard S, Marek T, et al. Health, well-being and burnout of ICU nurses on 12- and 8-h shifts. Work Stress 1996;10:251-6

9. Chen J, Davis KG, Daraiseh NM, et al. Fatigue and recovery in 12hour dayshift hospital nurses. J Nurs Manag 2014;22:593-603.

10. Geiger-Brown J, Rogers VE, Trinkoff AM, et al. Sleep, sleepiness, fatigue, and performance of 12-hour-shift nurses. Chronobiol Int 2012;29:211-9.

11. Stone PW, Du Y, Cowell R, et al. Comparison of nurse, system and quality patient care outcomes in 8-hour and 12-hour shifts. Med Care 2006;44:1099-106.

12. Battle $C$, Temblett P. 12-Hour nursing shifts in critical care: $A$ service evaluation. J Intensive Care Soc 2018;19:214-8.

13. Gupta N, Diallo K, Zurn P, et al. Assessing human resources for health: what can be learned from labour force surveys? Hum Resour Health 2003;1:5.

14. OECD. OECD Reviews of Health Care Quality: Norway 2014. OECD Publishing, Paris 2014

15. Ose SO. Using Excel and Word to structure qualitative data. J App/ Soc Sci 2016;10:147-62.

16. Kundi M, Koller M, Stefan $\mathrm{H}$, et al. Attitudes of nurses towards 8-h and 12-h shift systems. Work Stress 1995;9:134-9.

17. Scott LD, Rogers AE, Hwang WT, et al. Effects of critical care nurses' work hours on vigilance and patients' safety. Am J Crit Care 2006;15:30-7.

18. Virtanen M, Kurvinen T, Terho K, et al. Work hours, work stress, and collaboration among ward staff in relation to risk of hospitalassociated infection among patients. Med Care 2009;47:310-8.

19. Wilson M, Permito R, English A, et al. Performance and sleepiness in nurses working 12-h day shifts or night shifts in a community hospital. Accid Anal Prev 2019;126.

20. Li P, Morris CJ, Patxot M, et al. Reduced tolerance to night shift in chronic shift workers: Insight From Fractal Regulation. Sleep 2017;40.

21. Ferguson SA, Dawson D. 12-h or 8-h shifts? It depends. Sleep Med Rev 2012;16:519-28.

22. Harris R, Sims S, Parr J, et al. Impact of $12 \mathrm{~h}$ shift patterns in nursing: a scoping review. Int J Nurs Stud 2015;52:605-34. 